\title{
Cesarean Section Surgical Site Infections in Sub-Saharan Africa: A Multi-Country Study from Medecins Sans Frontieres
}

\author{
Kathryn Chu $\cdot$ Rebecca Maine $\cdot$ Miguel Trelles
}

Published online: 31 October 2014

(C) Société Internationale de Chirurgie 2014

\begin{abstract}
Background Surgical site infections (SSI) are a significant cause of post-surgical morbidity and mortality and can be an indicator of surgical quality. The objectives of this study were to measure post-operative SSI after cesarean section (CS) at four sites in three sub-Saharan African countries and to describe the associated risk factors in order to improved quality of care in low and middle income surgical programs.

Methods This study included data from four emergency obstetric programs supported by Medecins sans Frontieres, from Burundi, the Democratic Republic of Congo (DRC), and Sierra Leone. Women undergoing from August 12010 to January 312011 were included. CS post-operative SSI data were prospectively collected. Logistic regression was used to model SSI risk factors.

Findings In total, 1,276 women underwent CS. The incidence of SSI was $7.3 \%$ (range 1.7-10.4 \%). $93 \%$ of SSI were superficial. The median length of stay of women without SSI was 7 days (range 3-63 days) compared to 21 days (range 5-51 days) in those with SSI $(p<0.001)$. In multivariate analysis, younger age, premature rupture of the membranes, and neonatal death were associated with an increased risk of SSI, while antenatal hemorrhage and the Lubutu, DRC project site were associated with a lower risk of developing an SSI.

Conclusions This study demonstrates that surgery can be performed with a low incidence of SSI, a proxy for surgical safety, in sub-Saharan Africa. Protocols such as perioperative antibiotics and basic infrastructure such as clean water and sterilization can be achieved. Simple data collection tools will assist policymakers with monitoring and evaluation as well as quality control assurance of surgical programs in low and middle income countries.
\end{abstract}

K. Chu

Médecins sans Frontières, 49 Jorrisen St, Braamfontein, Johannesburg 2017, South Africa

K. Chu $(\bowtie)$

PO Box 154, Elgin 7180, Republic of South Africa

e-mail: Kathryn_chu@yahoo.com

R. Maine

Department of Surgery, University of California San Francisco,

San Francisco, USA
R. Maine

Program in Global Surgery and Social Change, Harvard Medical

School \& Boston Children's Hospital, Boston, USA

M. Trelles

Médecins sans Frontières, rue Dupré 94, 1090 Brussels, Belgium 


\section{Background}

Surgery is now recognized as an important component of public health in low and middle income countries (LMIC) [1-3]. As program managers expand their surgical capacity, measuring the quality of surgical care in these settings will be essential. However, finding the appropriate indicators is challenging [4]. High income countries (HIC) have elaborate monitoring and evaluation systems that measure quality on various levels including structure, process, and outcomes [5]. LMIC are resource limited and may only have rudimentary data collection systems. Moreover, some of these programs are emergency in nature, with even more limitations. Therefore, having systems in place to ensure quality of care ahead of time is important.

In-hospital mortality can be one quality indicator but for many procedures is less than $1 \%$; therefore is not always a sensitive measure [5, 6]. Surgical site infections (SSI) are a significant cause of post-surgical morbidity and mortality and can be an indicator of surgical quality. SSI are the most common nosocomial infection in sub-Saharan Africa (SSA) [7]. Risk factors for post-operative SSI are multi-factorial and include the type of surgical procedure, the length of operation, and the patient's prior co-morbidities. In one meta-analysis, SSI in Africa were reported to be higher than in HIC [7].

In most LMIC, emergency obstetric care, including cesarean section (CS), comprises a large proportion of surgical activity $[8,9]$. An estimated 18.5 million CS are performed worldwide each year. [10]. In HIC, post-CS SSI incidence ranges from 5 to $11.2 \%$ [11-14].

Medecins sans Frontieres (MSF) is a humanitarian medical organization that provides emergency surgical care. Approximately $26 \%$ of operative procedures are CS [15].

The primary objective of this study was to measure postoperative SSI after CS at four sites in three LMIC African countries. The secondary objective was to describe risk factors associated with SSI.

\section{Methods}

Study setting and sites

This study included data from four emergency obstetric programs supported by MSF from Burundi, the Democratic Republic of Congo, and Sierra Leone (Table 1). The study site and population have been described elsewhere [16]. All care was provided free of charge and administered with the permission of the local health authorities. All sites had electricity, clean water, sterilization units, operating rooms,
Table 1 Characteristics of participating hospitals

\begin{tabular}{cllll}
\hline Location & Hospital & Type & Catchment & $\begin{array}{c}\text { Health } \\
\text { centers }\end{array}$ \\
\hline $\begin{array}{c}\text { Masisi, } \\
\text { DRC }\end{array}$ & $\begin{array}{c}\text { Masisi General } \\
\text { Hospital }\end{array}$ & $\begin{array}{c}\text { MSF- } \\
\text { supported }\end{array}$ & 337,000 & 29 \\
$\begin{array}{c}\text { Lubutu, } \\
\text { DRC } \\
\text { Lubutu General } \\
\text { Hospital }\end{array}$ & $\begin{array}{c}\text { MSF- } \\
\text { supported }\end{array}$ & 103,000 & 18 \\
$\begin{array}{c}\text { Kabezi, } \\
\text { Burundi }\end{array}$ & CURGO & $\begin{array}{c}\text { MSF } \\
\text { hospital }\end{array}$ & 581,000 & 55 \\
$\begin{array}{c}\text { Bo, Sierra } \\
\text { Leone }\end{array}$ & $\begin{array}{c}\text { Gondama } \\
\text { Referral Center }\end{array}$ & $\begin{array}{c}\text { MSF } \\
\text { hospital }\end{array}$ & 302,000 & 24 \\
\hline
\end{tabular}

DRC Democratic Republic of Congo, MSF Medecins sans Frontieres, CURGO Centre d'Urgence Gynéco-Obstétrique

post-operative surgical wards, post-anesthesia care units, blood banks, anesthetics, analgesics, and antibiotics. CS was performed by expatriate and local general surgeons, obstetricians, and general doctors with surgical skills. Anesthesia was provided by nurse anesthetists and anesthesiologists. In all four programs, MSF was the only provider of comprehensive emergency obstetric care in the catchment area although other health facilities performed vaginal deliveries and occasional $\mathrm{CS}$.

\section{Study population}

Women undergoing CS from August 12010 to January 31 2011 were included in this study. All CS were performed according to perioperative protocols established by MSF. The abdomen, pelvis, perineum, and lower extremities were cleaned with povidone-iodine $10 \%$ prior to incision. All women were given cefazolin $1 \mathrm{~g}$ pre-operatively. Women with premature rupture of the membranes or fever were given amoxicillin with clavulanic acid after the procedure. The uterus and fascia were closed with absorbable polyglycolic acid in a running fashion. Non-absorbable sutures were removed on post-operative day 7 .

\section{Data collection}

Data were prospectively collected using a standardized paper form and then entered into an electronic database. Baseline characteristics on age, program site, gravida, parity, and indication for CS were collected.

Data on the CS procedure included: urgent or delayed, type of incision (midline or low transverse), suture used for skin closure (absorbable or non-absorbable), and closure style (interrupted or continuous suture).

Indications for CS were classified as obstructed labor, pre-eclampsia/eclampsia, uterine rupture, antepartum hemorrhage (placenta previa or placental abruption), 
Table 2 Demographic characteristics of women undergoing cesarean section

\begin{tabular}{|c|c|c|c|c|c|}
\hline Site & Masisi & Lubutu & Bo & Kabezi & Total \\
\hline$n$ & 446 & 174 & 338 & 318 & 1,276 \\
\hline Median age (IQR) & $25(20-30)$ & $20(18-24)$ & $20(17-25)$ & $25(21-30)$ & $25(20-30)$ \\
\hline Median parity & $4(2-7)$ & $2(1-4)$ & $2(0-4)$ & $2(1-4)$ & $2(1-5)$ \\
\hline Emergency & $415(93)$ & $164(94)$ & $333(99)$ & 317 (99) & $1,229(96)$ \\
\hline Median length of stay & $7(7-9)$ & $7(5-8)$ & $5(5-7)$ & $9(7-12)$ & $7(6-9)$ \\
\hline Maternal death & $2(0.5)$ & $0(0)$ & $4(1)$ & $1(0.3)$ & $7(0.5)$ \\
\hline Early neonatal death & $54(12)$ & $19(11)$ & $72(21)$ & $29(9)$ & $174(14)$ \\
\hline Post-operative infection rate & $32(7)$ & $3(2)$ & $25(7)$ & $33(10)$ & $93(7)$ \\
\hline $\mathrm{CS}$ rates & 5.5 & 7.9 & 16.8 & 4.1 & 6.2 \\
\hline
\end{tabular}

previous CS, cephalopelvic disproportion, breech, malpresentation (transverse lie, face presentation, and arm prolapse), multiple gestation (twins/triplets), cord prolapse, genital herpes, fetal distress, and other. For purposes of the analysis, prolonged labor and cephalopelvic disproportion were re-categorized as obstructed labor and malpresentation and breech as poor presentation. Outcome data on maternal and early neonatal death were documented. Maternal death was defined as death of the mother during hospitalization. Neonatal death was defined as death of an infant during hospitalization.

SSI were determined by physicians on the post-cesarean section ward. SSI were categorized as superficial or deep. A superficial wound infection was defined as infection of the skin and superficial tissues of the incision. Deep space infection was defined as infection involving the deep tissues such as the fascia and muscle layers [17]. The use of peri-operative antibiotics, the presence of premature rupture of membranes, and the type of treatment of the SSI provided were recorded. Patients were followed until the date of discharge. Referral clinics and the hospital kept records of any patients returning with delayed SSI. Treatment was recorded as observation only, antibiotics, opening of the wound at the bedside, re-operation, or other. Outcome of the SSI was categorized as resolved, improved, or worsened.

\section{Statistical analysis}

Baseline characteristics were described using medians and interquartile ranges (IQRs) for continuous variables and counts and percentages for categorical data. Logistic regression was used to model determinants of SSI. Variables considered in the analysis included age, parity, program site, indication for $\mathrm{CS}$, elective or emergent $\mathrm{CS}$, premature rupture of membranes, incision type (lowtransverse vs midline), use of post-operative antibiotics, type of wound closure (continuous vs interrupted), and type of suture (permanent vs absorbable) used for closure.
Factors with a $p$ value of 0.2 or smaller on univariate analysis were included in the multivariate model. Postoperative antibiotics were included a priori. A backwards selection algorithm was used to confirm goodness of fit. All tests and confidence intervals were considered to be significant at a $p \leq 0.05$. All analyses were performed using STATA 12 (College Station, TX, USA).

\section{Ethics}

Ethical approval was given by an independent Ethics Review Board that screens research proposals by MSF.

\section{Results}

In total, 1,276 women underwent CS. The median age was 25 (IQR 20-30) years and median parity was 2 (1-5). Table 2 lists the demographic characteristics for each program. There was full adherence to surgical site cleaning and prophylactic antibiotics. Half $(n=635,50 \%)$ of incisions were low transverse and half $(n=641,50 \%)$ were lower midline. Permanent suture was used to close the incision in $77.4 \%(n=987)$ cases; continuous suturing technique was used in $40.7 \%(n=519)$. All subjects $(n=1,276)$ received peri-operative antibiotics. The incidence of SSI was $7.3 \% \quad(n=93$, range $1.7-10.4 \%)$ (Table 3). The median time to onset of SSI was postoperative day 6 (range $2-17$ ). Most ( $n=87,93.5 \%$ ) SSI were superficial. Of all infections, 7 improved after observation $(7.5 \%), 52(56.0 \%)$ resolved with antibiotics, $28(30.1 \%)$ required opening of the wound with antibiotics, and $6(6.5 \%)$ required re-operation. The median length of hospital stay of women without SSI was 7 days (range 3-63 days) compared to 21 days (range 5-51 days) in those with SSI $(p<0.001)$. No women were referred from the outpatient or referral clinics for post-operative SSI after discharge. 
Table 3 Type and management of surgical site infections

\begin{tabular}{llr}
\hline & $n / \mathrm{N}$ & $\%$ \\
\hline Type of SSI & & \\
Superficial & $85 / 93$ & 91.4 \\
Deep & $7 / 93$ & 7.5 \\
Unknown & $1 / 93$ & 1.1 \\
Treatment for SSI & & \\
Antibiotics only & $52 / 93$ & 56.0 \\
Opening of wound & $28 / 93$ & 30.1 \\
Surgery & $6 / 93$ & 6.5 \\
Observation & $7 / 93$ & 7.5 \\
\hline
\end{tabular}

SSI surgical site infection

Associations with surgical site infections

In multivariate analysis, younger age (adjusted odds ratio $(\mathrm{aOR})=2.1,95 \%$ confidence interval $(\mathrm{CI})$ 1.2-3.6), premature rupture of membranes $(\mathrm{aOR}=2.1,95 \% \mathrm{CI}$ 1.3-3.4), and neonatal death $(\mathrm{aOR}=2.7,95 \%$ CI 1.5-5.0) were associated with increased risk of SSI, while antenatal hemorrhage $(\mathrm{aOR}=0.2,95 \% 0.5-1.0)$ and the Lubutu, DRC project site $(\mathrm{aOR}=0.3,95 \% \mathrm{CI} 0.1-0.9)$ were associated with a lower risk of SSI (Table 4). Maternal death was not associated with SSI; however, most deaths occurred in the first $48 \mathrm{~h}$, probably too soon before SSI could develop.

\section{Discussion}

CS saves millions of lives worldwide and is an essential surgical procedure that should be available to rich and poor women alike. In addition, CS is one of the 29 WHO-recommended surgical procedures that should be accessible at the district level worldwide [18]. SSI can be a proxy for quality surgical care, especially in LMIC where other quality measures are not available. In this study, we demonstrate that post-operative SSI after CSs in four African hospitals were low and comparable to those in HIC [1114]. This reassures MSF program managers that the organizations' SSI prevalence is within acceptable international standards and their standard protocols across projects for peri-operative antibiotics, sterilization, and wound care, are appropriate. Moreover, the study demonstrates that CS can be performed in LMIC settings with an acceptable level of care.

The SSI incidence in this study is lower than reported by other LMIC settings [19, 20]. One of the reasons could be the high uptake of antibiotics use which has been shown to decrease SSI by $39 \%$ [21].
Risk factors were identified in order to reduce SSI. Younger age was associated with SSI. A study in England also demonstrated an increased risk SSI for younger women [22]. Non- CS studies have demonstrated an association between age $>65$ years and SSI; however, in this study, all women were younger than 50 years of age. Perhaps factors associated with younger age such as poorer nutrition, which were not documented in this study, may have been associated with SSI. Premature rupture of membranes was associated with SSI which has also been shown in other studies [19, 23, 24]. Neonatal death was associated with SSI; no clear link has previously been demonstrated. Antenatal hemorrhage was protective against SSI for unclear reasons. Other studies have demonstrated that intra-operative blood loss and post-operative hematoma are associated with SSI [13, 20]. However, associations with antenatal hemorrhage have not been reported. Factors that were not examined in this study that may have been confounders included poor antenatal care, diabetes, or obesity.

The Lubutu, DRC project site had the lowest SSI $(1.7 \%)$ and was protective against SSI on multivariate analysis. Conversely, the Kabezi, Burundi site had the highest SSI (10.4\%) and trended toward being a SSI risk factor although not statistically significant in the multivariate model. One explanation might be that Kabezi is only a referral center for high risk pregnancies while Lubutu hospital cares for community obstetrical patients as well. Therefore, the women cared for at Kabezi have more complicated pregnancies and might be at higher risk for SSI.

Women who had SSI stayed in hospital a significantly longer amount of time (21 vs 7 days) post-operatively than those who did not. SSI leads to increased treatment time and possible reoperation. Moreover, in hospitals where resources are limited, having patients stay for 2 weeks longer, can be a burden on the healthcare system. Therefore, reducing SSI will reduce length of stay and morbidity, allow women to return to their families earlier, and allow other patients to be treated.

There are limitations to this study. Characteristics such as HIV status, diabetes, and other patient co-morbidities and intra-operative factors such as length of operation and blood loss were not measured and may have influenced SSI. Since women were not systematically followed after discharge, the SSI incidence may have been underestimated. However, in other studies, $95 \%$ of SSI were diagnosed before discharge and at a median of 6 days postCS which is similar to our study [19]. Moreover, in SSA, CS patients stay longer, on average, 3 days longer postoperatively (6 vs 3 days) because of the difficulty in returning to the hospital in case of complications. [25] This would increase the likelihood that the majority of post- 
Table 4 Factors associated with surgical site infection after cesarean section

\begin{tabular}{|c|c|c|c|c|c|c|c|c|}
\hline & \multirow[t]{2}{*}{$n / \mathrm{N}$} & \multirow[t]{2}{*}{$\%$} & \multicolumn{2}{|l|}{ Unadjusted } & \multirow[t]{2}{*}{$p$} & \multicolumn{2}{|c|}{ Adjusted } & \multirow[t]{2}{*}{$p$} \\
\hline & & & OR & $95 \% \mathrm{CI}$ & & $\mathrm{aOR}$ & $95 \% \mathrm{CI}$ & \\
\hline \multicolumn{9}{|l|}{ Age (years) } \\
\hline$\leq 30$ & $76 / 906$ & 8.4 & 1.9 & $(1.1-3.3)$ & 0.020 & 2.1 & $(1.2-3.6)$ & 0.013 \\
\hline$>30$ & $17 / 370$ & 4.6 & 1.0 (reference) & & & & & \\
\hline \multicolumn{9}{|l|}{ Program } \\
\hline Masisi, DRC & $32 / 446$ & 7.2 & 1.0 (reference) & & & & & \\
\hline Lubutu, DRC & $3 / 174$ & 1.7 & 0.2 & $(0.1-0.8)$ & 0.015 & 0.3 & $(0.1-0.9)$ & 0.038 \\
\hline Bo, Sierra Leone & $25 / 338$ & 7.4 & 1.0 & $(0.6-1.8)$ & 0.869 & 1.0 & $(0.6-1.9)$ & 0.901 \\
\hline Kabezi, Burundi & $33 / 318$ & 10.4 & 1.5 & $(0.9-2.5)$ & 0.120 & 1.8 & $(0.9-3.4)$ & 0.078 \\
\hline \multicolumn{9}{|l|}{ Post-op abx } \\
\hline Yes & $64 / 812$ & 7.9 & 1.2 & $(0.8-2.0)$ & 0.300 & 1.4 & $(0.8-2.5)$ & 0.312 \\
\hline No & $29 / 461$ & 6.3 & 1.0 (reference) & & & & & \\
\hline Unknown & $0 / 3$ & 0 & - & - & - & & & \\
\hline \multicolumn{9}{|l|}{ Suture } \\
\hline Permanent & $76 / 987$ & 7.7 & 1.3 & $(0.8-2.3)$ & 0.300 & - & - & - \\
\hline Absorbable & $17 / 288$ & 5.9 & 1.0 (reference) & & & & & \\
\hline \multicolumn{9}{|l|}{ Technique } \\
\hline Continuous & $36 / 519$ & 6.9 & 0.91 & $(0.6-1.4)$ & 0.705 & & & \\
\hline Interrupted & $57 / 756$ & 7.5 & 1.0 (reference) & & & & & \\
\hline \multicolumn{9}{|l|}{ Incision } \\
\hline Pfannenstiel & $43 / 635$ & 6.8 & 0.86 & $(0.6-1.3)$ & 0.480 & - & - & - \\
\hline Midline & $50 / 641$ & 7.8 & 1.0 (reference) & & & & & \\
\hline \multicolumn{9}{|l|}{ Rupture of membranes } \\
\hline Premature rupture of membranes & $40 / 287$ & 14.0 & 2.8 & $(1.8-4.4)$ & $<0.001$ & 2.1 & $(1.3-3.4)$ & 0.002 \\
\hline No membrane rupture & $53 / 989$ & 5.4 & 1.0 (reference) & & & & & \\
\hline \multicolumn{9}{|l|}{ Neonatal Death } \\
\hline Yes & $22 / 174$ & 12.6 & 2.1 & $(1.2-3.5)$ & 0.004 & 2.7 & $(1.5-5.0)$ & 0.001 \\
\hline No & $71 / 1102$ & 6.4 & 1.0 (reference) & & & & & \\
\hline \multicolumn{9}{|l|}{ Procedure } \\
\hline Delayed & $1 / 47$ & 2.1 & 1.0 (reference) & & & & & \\
\hline Urgent & $92 / 1229$ & 7.5 & 3.7 & $(0.5-27.3)$ & 0.195 & 2.2 & $(0.3-17.7)$ & 0.463 \\
\hline Indications & & & & & & - & - & - \\
\hline Obstructed Labor & $38 / 399$ & 9.5 & 1.0 (reference) & & & - & - & - \\
\hline Pre-eclampsia/eclampsia & $2 / 31$ & 6.45 & 0.7 & $(0.2-2.9)$ & 0.573 & 0.9 & $(0.2-4.0)$ & 0.852 \\
\hline Uterine rupture & $10 / 117$ & 8.6 & 0.9 & $(0.4-2.4)$ & 0.990 & 0.6 & $(0.3-1.4)$ & 0.234 \\
\hline Antepartum hemorrhage & $2 / 101$ & 2 & 0.2 & $(0.05-0.8)$ & 0.025 & 0.2 & $(0.5-1.0)$ & 0.050 \\
\hline Previous cesarean section & $12 / 184$ & 6.5 & 0.7 & $(0.3-1.3)$ & 0.232 & 0.9 & $(0.4-1.9)$ & 0.787 \\
\hline Malpresentation & $15 / 233$ & 6.4 & 0.7 & $(0.4-1.2)$ & 0.180 & 0.7 & $(0.4-1.3)$ & 0.241 \\
\hline Multiple gestation & $0 / 26$ & 0 & - & - & - & - & - & - \\
\hline Cord prolapse & $3 / 39$ & 7.7 & 0.8 & $(0.2-2.7)$ & 0.708 & 0.7 & $(0.2-2.4)$ & 0.535 \\
\hline Fetal distress & $11 / 128$ & 8.6 & 0.9 & $(0.4-1.8)$ & 0.753 & 1.0 & $(0.5-2.0)$ & 0.957 \\
\hline Other & $0 / 18$ & 0 & - & - & - & - & - & - \\
\hline \multicolumn{9}{|l|}{ Parity } \\
\hline$\leq 6$ & $80 / 1083$ & 7.4 & 1.0 (reference) & & & - & - & - \\
\hline$>6$ & $13 / 193$ & 6.7 & 0.9 & $(0.5-1.7)$ & 0.749 & - & - & - \\
\hline
\end{tabular}

A total of 1,253 patients were included in the final multivariate regression model Bold values are statistically significant $(P<0.05)$ 
operative SSI were captured prior to discharge. No patients were referred from the outpatient clinics after discharge for SSI, although this could also have been underreported.

In conclusion, this study demonstrates that surgery can be performed with a low incidence of SSI in SSA, a proxy for surgical safety. Although resources are limited, simple protocols such as perioperative antibiotics and basic equipment such as clean water and sterilization can be achieved even in these settings. While outcomes are more challenging to capture, simple data collection such as inhospital mortality and SSI are possible. This can assist policymakers with monitoring and evaluation as well as quality control assurance of surgical programs in LMIC.

Acknowledgements The authors would like to thank all the MSF field teams in Democrati Republic of Congo, Sierra Leone, and Burundi for their assistance on this study and their excellent care of our patients.

\section{Conflict of interest None.}

\section{References}

1. Wong EG, Kamara TB, Groen RS, Zogg CK, Zenilman ME, Kushner AL (2014) Prevalence of surgical conditions in individuals aged more than 50 years: a cluster-based household survey in Sierra Leone. World J Surg. doi:10.1007/s00268-0142620-1

2. Groen RS, Samai M, Petroze RT, Kamara TB, Cassidy LD, Joharifard S, Yambasu S, Nwomeh BC, Kushner AL (2013) Household survey in Sierra Leone reveals high prevalence of surgical conditions in children. World J Surg 37:1220-1226. doi:10.1007/s00268-013-1996-7

3. Petroze RT, Groen RS, Niyonkuru F, Mallory M, Ntaganda E, Joharifard S, Guterbock TM, Kushner AL, Kyamanywa P, Calland JF (2013) Estimating operative disease prevalence in a lowincome country: results of a nationwide population survey in Rwanda. Surgery 153:457-464

4. Chu KM, Trelles M, Ford NP (2011) Quality of care in humanitarian surgery. World J Surg. 35:1169-1172; discussion 1173-1164. Doi:10.1007/s00268-011-1084-9

5. Birkmeyer JD, Dimick JB, Birkmeyer NJ (2004) Measuring the quality of surgical care: structure, process, or outcomes? J Am Coll Surg 198:626-632

6. Chu KM, Ford N, Trelles M (2010) Operative mortality in resource-limited settings: the experience of Medecins Sans Frontieres in 13 countries. Arch Surg 145:721-725

7. Bagheri Nejad S, Allegranzi B, Syed SB, Ellis B, Pittet D (2011) Health-care-associated infection in Africa: a systematic review. Bull World Health Organ 89:757-765

8. Ivers LC, Garfein ES, Augustin J, Raymonville M, Yang AT, Sugarbaker DS, Farmer PE (2008) Increasing access to surgical services for the poor in rural Haiti: surgery as a public good for public health. World J Surg 32:537-542. doi:10.1007/s00268008-9527-7

9. Ozgediz D, Galukande M, Mabweijano J, Kijjambu S, Mijumbi C, Dubowitz G, Kaggwa S, Luboga S (2008) The neglect of the global surgical workforce: experience and evidence from Uganda. World J Surg 32:1208-1215. doi:10.1007/s00268-0089473-4

10. Luz Gibbons JMBn, Jeremy A Lauer, Ana P Betrán, Mario Merialdi, Fernando Althabe (2010) The global numbers and costs of additionally needed and unnecessary caesarean sections performed per year: overuse as a barrier to universal coverage. World Health Organization

11. Griffiths J, Demianczuk N, Cordoviz M, Joffe AM (2005) Surgical site infection following elective Caesarian section: a casecontrol study of postdischarge surveillance. J Obstet Gynaecol Can 27:340-344

12. Johnson A, Young D, Reilly J (2006) Caesarean section surgical site infection surveillance. J Hosp Infect 64:30-35

13. Olsen MA, Butler AM, Willers DM, Devkota P, Gross GA, Fraser VJ (2008) Risk factors for surgical site infection after low transverse cesarean section. Infect Control Hosp Epidemiol 29:477-484 discussion 485-476

14. Webster J (1988) Post-caesarean wound infection: a review of the risk factors. Aust N Z J Obstet Gynaecol 28:201-207

15. Wong EG, Trelles M, Dominguez L, Gupta S, Burnham G, Kushner AL (2014) surgical skills needed for humanitarian missions in resource-limited settings: common operative procedures performed at Medecins Sans Frontieres facilities. Surgery

16. Chu K, Cortier H, Maldonado F, Mashant T, Ford N, Trelles M (2012) Cesarean section rates and indications in sub-Saharan Africa: a multi-country study from Medecins sans Frontieres. PLoS One 7:e44484

17. Horan TC, Gaynes RP, Martone WJ, Jarvis WR, Emori TG (1992) CDC definitions of nosocomial surgical site infections, 1992: a modification of CDC definitions of surgical wound infections. Infect Control Hosp Epidemiol 13:606-608

18. Tool for Situational Analysis to Assess Emergency and Essential Surgical Care [http://www.who.int/surgery/publications/en/]

19. Amenu D, Belachew T, Araya F (2011) Surgical site infection rate and risk factors among obstetric cases of Jimma university specialized hospital, southwest Ethiopia. Ethiop J Health Sci 21:91-100

20. Jido T, Garba I (2012) Surgical-site infection following cesarean section in Kano, Nigeria. Ann Med Health Sci Res 2:33-36

21. Smaill FM, Gyte GM (2010) Antibiotic prophylaxis versus no prophylaxis for preventing infection after cesarean section. Cochrane Database Syst Rev CD007482. doi:10.1002/14651858. CD007482.pub2

22. Wloch $\mathrm{C}$, Wilson J, Lamagni $\mathrm{T}$, Harrington $\mathrm{P}$, Charlett $\mathrm{A}$, Sheridan E (2012) Risk factors for surgical site infection following caesarean section in England: results from a multicentre cohort study. BJOG 119:1324-1333

23. Gong SP, Guo HX, Zhou HZ, Chen L, Yu YH (2012) Morbidity and risk factors for surgical site infection following cesarean section in Guangdong Province, China. J Obstet Gynaecol Res 38:509-515

24. Schneid-Kofman N, Sheiner E, Levy A, Holcberg G (2005) Risk factors for wound infection following cesarean deliveries. Int $\mathrm{J}$ Gynaecol Obstet 90:10-15

25. Wilson J, Wloch C, Saei A, McDougall C, Harrington P, Charlett A, Lamagni T, Elgohari S, Sheridan E (2013) Inter-hospital comparison of rates of surgical site infection following caesarean section delivery: evaluation of a multicentre surveillance study. J Hosp Infect 84:44-51 